\title{
The functions of phonology in the acquisition of reading: Lexical and sentence processing
}

\author{
RHONA S. JOHNSTON \\ St. Andrews University, St. Andrews, Fife, Scotland \\ G. BRIAN THOMPSON \\ Victoria University of Wellington, Wellington, New Zealand \\ CLAIRE M. FLETCHER-FLINN \\ University of Auckland, Auckland, New Zealand \\ and \\ CHRISTOPHER HOLLIGAN \\ University of Paisley, Craigie Campus, Ayr, Scotland
}

\begin{abstract}
It has been clairned (V. Coltheart, Laxon, Rickard, \& Elton, 1988) that learners as well as skilled readers use phonology for multiple functions in reading-for-meaning tasks. This claim was examined using lexical decision and sentence evaluation tasks. It was found in the first experiment that the type of instruction learners had received determined whether there was prelexical use of phonology in responding to items out of sentence context. Type of instruction had no effect when the items were in context. In the second experiment, performances on a homophone sentence evaluation task and a homophone semantic decision task, which excluded sentence processing, were examined. The results suggest that phonology served the function of access to lexical meanings in addition to any function in postlexical sentence processing. The obtained relationships between relative frequencies of the presented and unpresented homophone mates and item accuracy on these tasks were inconsistent with exclusive use of "direct access" but consistent with access of lexical meanings via phonology and application of a "spelling-check" procedure when multiple homophonic meanings are activated.
\end{abstract}

The functions of phonology in the silent reading of sentences for meaning have been ascribed to either lexical access (i.e., the retrieval of individual words and their meanings; see V. Coltheart, Avons, \& Trollope, 1990; Daneman \& Stainton, 1991) or to temporary postlexical phonological storage for syntactic and semantic analysis of sentences (Kleiman, 1975; Liberman, Liberman, Mattingly, \& Shankweiler, 1980). While there is adequate evidence that phonology is in fact used in silent reading of sentences (V. Coltheart et al., 1990; V. Coltheart \& Laxon, 1990; V. Coltheart, Laxon, Rickard, \& Elton, 1988; Doctor \& Coltheart, 1980; Johnston, Rugg, \& Scott, 1987; Treiman, Freyd, \& Baron, 1983), limited

This research was supported by grants to R.S.J. and G.B.T. from the British Council, New Zealand, and by grants to G.B.T. from the Internal Grants Committee, Victoria University of Wellington. The authors thank the children and staff of the participating schools in New Zealand and Scotland for their willing cooperation throughout this study. Correspondence should be addressed to R. S. Johnston, School of Psychology, University of St. Andrews, St. Andrews KY 69 JU, Fife, Scotland (e-mail: rjl@ $@$ st-andrews.ac.uk), or to G. B. Thompson, Department of Education, Victoria University of Wellington, P.O. Box 600, Wellington, New Zealand (e-mail: brian.thompson@vuw.ac.nz). progress has been made in accumulating evidence about which functions the phonology serves.

One function of phonology is print-to-sound translation for lexical access, carried out using subword levels of orthography and phonology. This is a prelexical function. Many different forms have been proposed for this function, some being rule-based assembly of phonological segments (M. Coltheart, Curtis, Atkins, \& Haller, 1993; V. Coltheart, Avons, Masterson, \& Laxon, 1991; Patterson \& Coltheart, 1987). In other accounts the print-to-sound prelexical function is served by distributed connections between subsymbolic orthographic and phonological elements (Seidenberg \& McClelland, 1989 , implemented section of model). In yet other accounts, print-to-sound translation may take multiple forms, at least during learning of the skill and depending on the type of instruction received (Thompson \& Fletcher-Flinn, 1993; Thompson \& Johnston, 1993). Much of the data gathered in support of these accounts derives from tasks using individually presented words, either for word-naming responses or lexical decisions (deciding whether a print stimulus is a word or nonword). In these tasks, access to some representation of the words is required, but in neither case does the task require access to the lexical meanings of the words. This 
is required, however, in the sentence evaluation task (deciding whether a print sentence is semantically accept$\mathrm{able}$ ) and in the semantic decision task (deciding whether the meaning of a print word matches that of a single word or phrase statement).

The reader may use phonological representations to access lexical meanings, irrespective of any prelexical use of phonology. This is postulated as the case in one of the processing routes in the models of reading presented by Patterson and Coltheart (1987), V. Coltheart et al. (1991), and M. Coltheart et al. (1993). In these models, in addition to a prelexical print-to-sound translation processing pathway and a direct pathway from representations for visual word recognition (the orthographic-input lexicon) to lexical meaning, there is a pathway from the orthographic-input lexicon to the phonological-output lexicon (representations of word pronunciations) from which is derived word meaning (via links with a phonological-input code in the V. Coltheart et al., 1991, model). This third processing route is described as "addressed phonological mediation" (V. Coltheart et al., 1991).

In reading sentences for meaning, which is the focus of the present experiments, there is yet another function for phonological representations. Following identification of the print word, phonological representations may be used for temporary storage of the words while the syntactic and semantic processes of sentence comprehension take place. The first purpose of these experiments was to examine the prelexical use of phonology in tasks that include the reading of sentences for meaning. Also focusing on these tasks, the second purpose, taken up in Experiment 2, was to distinguish experimentally between the function of phonology in accessing lexical meanings and in postlexical sentence processing.

Some recent studies have used concurrent articulation in an attempt to disambiguate the different functions of phonological processing used in reading sentences for meaning. Although V. Coltheart et al. (1990) concluded that articulatory suppression disrupts the prelexical function of phonology for print-to-sound translation, the locus of these effects in reading is currently the subject of much debate. Concurrent articulation may in fact interfere with postlexical phonological functions, as Besner (1987) suggests.

In a categorization task in which subjects decide whether a word is an exemplar of a category name, Van Orden, Johnston, and Hale (1988) found that skilled readers made as many false positive categorization errors to homophonic words as to pseudohomophonic nonwords (i.e., to "a metal-steal" vs. "a vehicle-jeap"). Because pseudohomophones are without a lexical representation for reading, they concluded that the prelexical function of phonology was the source of errors for both types of items. V. Coltheart et al. (1991), however, found that the results of Van Orden et al. (1988) were replicated only when subjects were given instructions that did not tell them to reject misspellings. Jared and Seidenberg (1991) have carried out a series of experi- ments on skilled readers with the same task (but provided correction to responses in practice trials). They concluded that homophony effects in the task are restricted to low-frequency items. They speculated, however, that learners would depend more than would skilled readers on the phonological activation of meaning. The categorization task used in their experiments has the advantage of requiring the reader to access lexical meanings, but it may well demand other processing strategies that make it unrepresentative of sentence reading.

V. Coltheart et al. (1988) examined the performance of skilled adult readers and learners on reading tasks in which subjects decided whether sentences made sense or not. Subjects at both reading levels showed homophony effects on sentences that contained pseudohomophones (e.g., "Her bloo dress was new") as well as those that contained homophones (e.g., "He through out the rubbish"). They concluded that, for both adults and children, phonology served a prelexical as well as a postlexical function in reading sentences for meaning. This interpretation is placed in doubt, however, by a subsequent report by V. Coltheart et al. (1990). Although they replicated the finding that adults showed a homophony effect in silent reading of sentences containing a homophone, they failed to find such effects in sentences with a target pseudohomophone, throwing doubt on the conclusion that skilled readers make prelexical use of phonology in reading sentences for meaning. Both this finding and the interpretation for learners in the 1988 study need further examination. Was the learners' prelexical use of phonology a product of the type of reading instruction received? Would learners exposed to other types of school instruction also make prelexical use of phonology? V. Coltheart et al. (1988) do not state the type of reading instruction received by the subjects in their experiment. It cannot be assumed that phonological information is used to the same extent by learners, independently of the type of instruction they receive. Sufficient evidence has accumulated to place such an assumption in doubt. While 8-year-olds who had learned to read by an explicit phonics method showed prelexical use of phonology in a pseudohomophone lexical decision task, those who had learned to read without explicit phonics instruction did not (Johnston \& Thompson, 1989; Thompson \& Johnston, 1993). Furthermore, in sentence-reading tasks, V. Coltheart and Laxon (1990) interpreted differences in results between subject samples of two experiments as indicating that prelexical use of phonology emerged later in children taught by a "language experience" approach than in those taught by an explicit phonics method. Experiment 1 was conducted to examine how general is the prelexical use of phonology in reading-formeaning tasks, directly comparing children who received widely differing types of reading instructionthat is, a method that includes explicit teaching of lettersound correspondences and a method that does not. However, in sentence reading, not all processes that involve phonology may entail the prelexical function. There 
are functions for phonology that follow access to the phonological representation of the word. The purpose of Experiment 2 was to distinguish experimentally between the function of access to lexical meanings and other functions of postlexical sentence processing in reading sentences for meaning.

Accuracy of performance was the dependent variable in these experiments. As was the case in previous studies on children's responses to sentence evaluation tasks, decision times were not recorded (V. Coltheart \& Laxon, 1990; V. Coltheart et al., 1988, Experiment 2; Doctor \& Coltheart, 1980; Johnston et al., 1987). Most studies of sentence evaluation with skilled adult readers have failed to find significant homophony effects on decision times for correct responses (Baron, 1973; V. Coltheart et al., 1988, Experiment 1). An exception is a study in which subjects were atypically told to sacrifice accuracy for speed; here, both increased errors and slower correct responses to sentences containing homophones were found (Treiman et al., 1983). Significant effects of homophony were found in the false positive errors in all these studies. Indeed, V. Coltheart et al. (1988) argue that the false acceptance of sentences that sound correct is the predicted outcome of phonological coding where comprehension is involved (i.e., phonological storage of the sentence leads to errors on some occasions because the wrong meaning of the homophone is accessed.) A further consideration is that, in responding to the sentence evaluation task, children have much higher error rates than do skilled adults, error rates being as high as $40 \%$. In addition, the proportion of responses that are correct but are very slow outliers would be expected to be at least $10 \%$. Conclusions based on decision times are not considered to be meaningful when the data are from less than $50 \%$ of relevant presented items (Jared \& Seidenberg, 1991, p. 365). In the lexical decision task, error rates are not so high, however, and pilot work was carried out to determine whether the correct rejection of pseudohomophones is slower than that of control nonwords for children and adults. ${ }^{1}$ The stimuli were derived according to Taft's (1982) criteria for strict matching of the visual similarity of the pseudohomophones and control nonwords to real words. A pseudohomophone effect was obtained in the error rates of 8-year-olds but not in their decision times for correct responses. Pseudohomophone effects were not obtained for either dependent variable for 11-year-olds and skilled adults, the latter result replicating that of Taft (1982).

\section{EXPERIMENT 1}

It has been found (Johnston \& Thompson, 1989) that learners receiving school reading instruction that includes explicit phonics teaching (i.e., the systematic teaching of the relationships between letter sequences and their pronunciations) showed a pseudohomophone effect in a lexical decision task. The learners incorrectly identified as words more nonwords that were homophonic with words (pseudohomophones) than nonwords that were not homophonic, but as visually similar, with real print words. Because nonwords have not received orthographic storage as lexical items, any activation of phonology in responding to them will entail a prelexical function for phonology. Learners at the same level of reading attainment who had not received explicit phonics instruction showed no pseudohomophone effect and, thus, no influence of the prelexical use of phonology in this task. The question examined in Experiment 1 was whether or not such learners also fail to show the influence of the prelexical function of phonology in sentencereading tasks. To enable comparison with earlier published experiments, the question was also examined for older, more experienced readers and for younger (8-yearold) learners. In the pseudohomophone sentence evaluation task, subjects decided whether or not each sentence made sense in its presented orthographic form. In addition to correct sentences, some sentences included a pseudohomophone (e.g., "There is blud on the floor"), whereas others included a matched control nonword (e.g., "The flowers are in blum early"). (No italics were in the stimuli.) The pseudohomophones and nonwords were matched for their visual-orthographic similarity to real print words. These items also appeared as isolated items (i.e., without sentence contexts) in a lexical decision task administered to the same samples of subjects.

The prelexical use of phonology by learners may be universal in sentence-reading tasks, irrespective of the type of instruction received. If this were the case, then it would be predicted that learners receiving reading instruction without an explicit phonics component, although showing no effects of the prelexical function of phonology in the pseudohomphone lexical decision task, would show such effects in the sentence evaluation task. That is, they would erroneously accept as making sense more of the sentences with pseudohomophones than the sentences with the control nonwords, although they would not make more errors to pseudohomophones than to control nonwords in the lexical decision task, where the items are presented out of context.

It is possible that readers could be using phonology for access to lexical meanings, although this does not involve the prelexical function of print-to-sound translation. In the models of Patterson and Coltheart (1987), V. Coltheart et al. (1991), and M. Coltheart et al. (1993), one of the processing routes is addressed phonological mediation. The phonological representation of a word (phonological-output lexicon) is retrieved as a stored entity as a consequence of activation of the stored orthographic representation of a familiar word. The phonological-output lexicon is linked with the semantic system; hence, meaning is accessed by this indirect route. By this account, homophony effects for (familiar) homophone words with irregular spelling-to-sound correspondences could depend on addressed phonological mediation and exclude the prelexical print-to-sound translation function of phonology. This translation function cannot fully determine the phonological form of such words. Consistent with this account is the finding 
of V. Coltheart et al. (1991) that among skilled readers homophony effects are greater in sentence evaluation tasks for homophones with regular spelling-to-sound correspondences than with irregular ones. An implication of the account is that learners' performance on sentence evaluation with homophones that have irregular spelling-to-sound-correspondences would be unaffected by their exposure to explicit phonics teaching, since this is intended to teach skills in the prelexical use of phonology. There are alternative accounts (Seidenberg \& McClelland, 1989; Van Orden, Pennington, \& Stone, 1990 ) in which computed sublexical phonology explains print-to-sound translation for words with regular and irregular spelling-to-sound correspondences, although many more learning exposures are required to enable identification of the latter. On the basis of the Patterson and Coltheart (1987) account, if exposure to phonics teaching were to influence performance on a sentence evaluation task with homophones that have irregular spelling-to-sound correspondences, as well as decision tasks with pseudohomophones, doubt would be placed on the claim that the effects of phonics instruction were specific to the prelexical function of phonology. To examine this question, a third task was administered. In this homophone sentence evaluation task, in addition to presentation of correct stimulus sentences, some sentences included an incorrect homophone that made the sentence sound correct (e.g., "The son is shining in the sky"), and others included a matched visual control word (e.g., "The sure is shining in the sky"). Both the target (son) and the matched control word (sure) had spelling that was irregular in the sense that simple grapheme-phoneme correspondences would not suffice to fully determine the sound of the word.

\footnotetext{
Method

Subjects. Two hundred and sixty-eight children ( 8 and 11 years old) were initially tested in four schools in the Fife and Lothian regions of Scotland. All of the children started to receive reading instruction on entry to school at the average age of 5 years. The reading programs in these schools included a strong "phonics" component, although the children's reading books were rarely overtly phonic. Starting at school entry, the sounds of the letters were systematically taught. After around 6 months of schooling, children were taught to sound and blend simple consonant-vowelconsonant words. This was typically followed in Years 2 and 3 by the explicit teaching of vowel and consonant digraphs and rules such as final $e$. Words were shown to the children in word families (e.g., coat, boat, goat) in nonsentence contexts. The children also read meaningful story texts from the start of schooling. When faced with an unfamiliar word in text, they were encouraged both to "sound it out" and to try to work it out from the context. The teaching of writing skills in these schools used to heavily emphasize the formation of letters and often involved the copying of stories from the blackboard. These skills were still considered important when the study was carried out, and the formation of letters was seen as a way of reinforcing letter-sound knowledge. Recently, however, there has also been a much more experiencebased approach, with children, for example, drawing a series of pictures and telling the story for the teacher to scribe, or picking out the words they need to write the story from a "sentence maker."
}

Two hundred children ( 8 and 11 years old) attending three schools in the Hutt area in New Zealand were also tested. These children also started to receive reading instruction on entry to school at 5 years of age. They were taught to read by a "book experience" method, which emphasizes as cues to word identification the semantic-syntactic context of the word and the initial letter of the word (the name of the letter more commonly than the corresponding sound). Instruction in explicit "phonics" was not included, insofar as the children did not receive explicit instruction in the pronunciation of sounds of isolated letters or in the correspondence between component letter sequences of words and their corresponding pronunciations. There was no instruction in assembly (blending of sounds). When component sounds of words were considered, this usually involved the child's listening to the sound corresponding to the initial letter of a word from a story text when the word was pronounced by the teacher. The essentials of this approach to reading instruction have been in common use in New Zealand for 30 years. Further details of the approach may be found in Thompson (1993). In the first few months at school, there was concurrent early emphasis on children's expressing themselves in written language. Also, it was common for teachers to encourage children to generate spellings from sounds of words.

Reading attainment levels in both samples were assessed on the Primary Reading Test, Level 2 (France, 1981), a group test of reading comprehension with Scottish norms. The children were also administered the group form of the English Picture Vocabulary Test 2 (Brimer \& Dunn, 1968) to assess aural vocabulary. The children at each age level were matched between samples on their range of reading scores, aural vocabulary standard scores $(M=$ $100, S D=15$ ), and chronological age, the matching being carried out within each group of boys and girls. After matching, the 8year-old group comprised 30 phonics-taught children ( 15 girls and 15 boys) and 30 nonphonics-taught children ( 15 girls and 15 boys). For the 11 -year-old group, there were 35 phonics-taught children ( 18 girls and 17 boys) and 35 nonphonics-taught children ( 18 girls and 17 boys). See Table 1 for means and standard deviations. All were English-speaking children. Low-achievement and superior readers were excluded. Non-Caucasian children were excluded from the New Zealand nonphonics sample for comparability with the British phonics sample.

Pseudohomophone lexical decision task. Twenty pairs of words were used to generate pseudohomophones and nonwords, according to Taft's (1982) criteria for matching visual similarity. The words post and lost, for example, were selected as having the same spelling of the vowel segment but different pronunciation. This meant the vowel $o$ could be replaced by the vowel digraph $o a$, generating "poast" (a pseudohomophone) and "loast" (matched control nonword as visually similar to a real word as is the pseudohomophone). The pseudohomophones share the phonology of a real word, but this is not the case for the visual control nonwords. The words from which these 20 experimental item pairs were generated were of similar mean frequency, $252(S D=425)$ for the pseudohomophones and $256(S D=608)$ for the visual control nonwords (Carroll, Davies, \& Richman, 1971, Grade 3 norms). Forty words were selected as fillers and were matched on word frequency to the words used to generate the pseudohomophones and nonwords, having mean frequencies of $230(S D=330)$ and $253(S D=582)$. The items were selected on the basis of a pilot administration to both Scottish and New Zealand adults who were asked to categorize the items according to whether or not they sounded like words. The experimental items are listed in Appendix A.

The items were presented in lowercase typescript on a page of a test booklet and were ordered so that half the pseudohomophones appeared in the first block of 40 items and half in the following block of 40 items. The matched nonword controls appeared in the complementary blocks of items. No more than three successive items were pseudohomophones or control nonwords, and no more 
Table 1

Means and Standard Deviations of Chronological Ages, Reading Ages, and Aural Vocabulary Scores of Subjects in Experiment 1

\begin{tabular}{|c|c|c|c|c|c|c|c|c|}
\hline & \multicolumn{4}{|c|}{ 8-Year-Olds } & \multicolumn{4}{|c|}{ 11-Year-Olds } \\
\hline & \multicolumn{2}{|c|}{ Phonics } & \multicolumn{2}{|c|}{ Nonphonics } & \multicolumn{2}{|c|}{ Phonics } & \multicolumn{2}{|c|}{ Nonphonics } \\
\hline & $M$ & $S D$ & $M$ & $S D$ & $M$ & $S D$ & $M$ & $S D$ \\
\hline $\begin{array}{l}\text { Chronological } \\
\text { age in years }\end{array}$ & 8.6 & 0.24 & 8.7 & 0.21 & 11.3 & 0.25 & 11.5 & 0.25 \\
\hline $\begin{array}{l}\text { Reading age } \\
\text { in years }\end{array}$ & 8.4 & 0.89 & 8.5 & 0.89 & 11.8 & 1.43 & 11.8 & 1.47 \\
\hline $\begin{array}{l}\text { Aural vocabulary } \\
\text { (standard score) }\end{array}$ & 99.0 & 11.3 & 98.4 & 9.4 & 99.1 & 11.0 & 100.3 & 16.1 \\
\hline
\end{tabular}

than three successive items were fillers. Two versions with different orderings of the 80 items were constructed so that in the group administration the children would not be able to copy responses from their neighbors. The order of items between blocks was counterbalanced between these two versions. In the group administration, the two versions were alternated between adjacently seated children.

Eight demonstration items appeared on the front of the children's booklets and were written on the classroom blackboard. The children were instructed that the task was to decide whether each item was a "real" or "made-up" word. Real words were to be given a tick; made-up words were to be given a cross. When a pseudohomophone appeared as a demonstration item, the experimenter said, "That sounds the same as the real word (example given) but it is spelt wrongly. It is a made-up word. It gets a cross." (The correct spelling of the word was not shown.) These instructions were considered necessary because children may not understand that incorrectly spelled items that sound like words are not acceptable as real words. When Johnston, Rugg, and Scott (1988) used these instructions, their 7-year-old subjects showed a smaller pseudohomophone effect than did Holligan and Johnston's (1988) 7-yearold subjects, who were given the same stimuli but who were not told that incorrect spelling was unacceptable. Both of these groups had received phonics instruction. There is evidence, therefore, that the present instructions do not inflate the homophony effect.

The children in the present experiment were instructed to do the task as accurately and as fast as possible. They were instructed to read silently, although a few of the 8 -year-old phonics-taught subjects were heard to be sounding out the items. This task was carried out at the beginning of the first test session and was followed by the picture vocabulary test and the reading test in the same session. On completion of each task or test, the subjects turned their response booklets back to the cover page, to avoid looking back and revising their responses.

Pseudohomophone sentence evaluation task. The pseudohomophone sentence evaluation task was similar to that used by Johnston et al. (1987) and V. Coltheart et al. (1988). The pseudohomophones and matched visual control nonwords from the lexical decision task were embedded in sentences (e.g., "Can you poast this letter?" "She has loast her bag"). The number of words in the pseudohomophone sentences and control nonword sentences was matched as closely as possible. In addition to the 20 pseudohomophone sentences and 20 control nonword sentences, 40 filler sentences (e.g., "The tree has fallen over") were constructed. The experimental items are listed in Appendix B.

This task was administered in a second session, $6-12$ days after the first. The presentation and ordering of items followed the same pattern as in the lexical decision task. Four demonstration items preceded the task. The children were told that the task was to read each sentence and decide whether or not it made sense. When a sentence with a pseudohomophone was considered in the demonstration, the experimenter said, "That sentence sounds all right, but this word (example given) is spelt wrongly. The sentence does not make sense, so we put a cross against it." (The children were not shown the correct spelling of the word.) The children read silently and were told to do the task as accurately and as fast as they could.

Homophone sentence evaluation task. The homophone sentence evaluation task was also similar to that used by Johnston et al. (1987) and V. Coltheart et al. (1988). Fifteen sentences containing homophones were generated (e.g., "The sun is shining in the sky"). The critical homophone was then substituted by its homophone mate (e.g., son) to generate a meaningless sentence that sounded correct (as in "The son is shining in the sky"). This was the sentence presented. Substitute words were homophonic in common pronunciations both in Scotland and in New Zealand. The original sentence was then used to generate a visual similarity control sentence by changing the homophone for a visually similar word (e.g., "The sure is shining in the sky"). The substituted words in the presented homophone sentence and the visual similarity control sentence were matched on visual similarity to the original word (unpresented homophone mate) using Weber's (1970) graphic similarity index, which gave mean values of 593 $(S D=119)$ for the homophones and $604(S D=114)$ for the control words. The mean word frequencies (Carroll et al., 1971, Grade 3 norms) were $136(S D=220)$ and $134(S D=182)$, respectively. For the original homophones (not presented), the mean was $342(S D=939)$. Both the stimulus homophones (e.g., son) and control words (e.g., sure) had irregular spelling-to-sound correspondences, insofar as they contained at least one graphemephoneme correspondence in which the pronunciation for the grapheme was not a typical one (irregular). In making this selection, consideration was given to the varieties of English pronunciations common in Scotland and New Zealand. The experimental items are listed in Appendix C. Fifteen pairs of filler sentences were constructed (e.g., "They made a seat in the garden" and "They made a swing in the garden"), making 30 filler sentences in all. The task was split into two parts, the first section being presented before the pseudohomophone sentence evaluation task and the second section afterward. No sentence appeared in the same section as its matched pair. Two versions of the task with different orderings of the 60 items were constructed to obviate subjects copying from neighbors. The order of items between the two sections was counterbalanced between these two versions. Instructions and four demonstration items were provided at the beginning of each section. The instructions followed the same form as in the pseudohomophone sentence evaluation task.

Word-meaning control task. Although it may be assumed that skilled adult readers can discriminate between and identify the print forms of the homophones and their respective meanings, it cannot be assumed that learners will do so with complete accuracy. A homophone effect in the sentence evaluation task could therefore be due to lack of knowledge of the print forms of the homophones and their meanings, relative to visual similarity control items. The word-meaning control task was designed to measure this aspect of the children's knowledge, not as some absolute or pure measure but in a form matched with the items of the homo- 
phone sentence evaluation task. The control task was a more systematic and objective version of that used by Doctor and Coltheart (1980) and Johnston et al. (1987). The homophone and control words from the homophone sentence evaluation task were each presented along with four response alternatives. For example, corresponding items for a homophone and a cont rol word were:

$$
\begin{array}{cc}
\text { son } & \text { sure } \\
\text { _ next } & \text { - beach } \\
\text { — light } & \text { - open } \\
\text { — child } & \text { - cold } \\
\text { _ push } & \text { - certain }
\end{array}
$$

In the case of the homophones, one of the response alternatives was the meaning (e.g., light) appropriate in the homophone sentence of the homophone sentence evaluation task. In the case of the control words, the sound of a word (e.g., /shore/) associated with one alternative (e.g., /beach/) was similar to the sound of the control word (e.g., /sure/). Alternatives included short phrases (up to four words) as well as single words. In view of the necessity to have the simplest possible vocabulary for the child subjects, the correct defining alternatives were abbreviated versions of the definitions given in several children's dictionaries. The items are listed in Appendix D. Not more than three successive items were of one type (homophone, control). If a homophone appeared in the first half of the 30 items, then its corresponding cont rol appeared in the second half, and vice versa. Two versions of the task were constructed with different orderings of the 30 items and of the response alternatives. The versions were alternated between adjacently seated children in the group administration of the task.

The children were told that this task involved choosing meanings for words. Four demonstration items were presented. They were told that they had to choose the best meaning for each word and to consider all the alternatives carefully before giving a tick to the best meaning. There were no speed requirements. The children were told to take their time with the task. The task was carried out at the end of the second test session so that it could not influence performance on the sentence evaluation task.

\section{Results}

Pseudohomophone lexical decision task. A threeway analysis of variance (ANOVA) for unequal cell numbers was carried out on the percentage of correct responses to the pseudohomophone lexical decision task. There was one within-subjects variable, stimulus type (pseudohomophones vs. matched control nonwords), and two between-subjects variables, group (children taught by phonics vs. nonphonics methods) and age ( 8 and 11-year-olds). See Table 2 for means and standard deviations. There was a main effect of age $[F(1,126)=$ $\left.27.60, M S_{\mathrm{e}}=132.75, p<.001\right]$, performance being superior for the older children. There was also a main effect of stimulus type $\left[F(1,126)=22.15, M S_{\mathrm{e}}=39.25\right.$, $p<.001]$, with more errors for pseudohomophones than for controls. However, there were significant interactions between age and stimulus type $[F(1,126)=12.36$, $\left.M S_{\mathrm{e}}=39.25, p<.001\right]$ and between group and stimulus type $\left[F(1,126)=4.73, M S_{\mathrm{e}}=39.25, p<.05\right]$. These were subsumed by a significant three-way interaction between age, group, and stimulus type $[F(1,126)=6.92$, $\left.M S_{\mathrm{e}}=39.25, p<.01\right]$. The main effect of group and the group $\times$ age interaction were not significant. An analysis was also carried out with items as a random variate. A significant three-way interaction between age, group, and stimulus type was again found in this analysis $\left[F(1,38)=16.44, M S_{\mathrm{e}}=10.86, p<.001\right]$. Tests of simple effects (planned comparisons) showed that the 8year-old phonics-taught children were less accurate at classifying pseudohomophones than at classifying matched control nonwords $[t(126)=6.31, p<.001$, for the analysis by subjects; $t(38)=9.60, p<.001$, for the analysis by items]. The 8 -year-old nonphonics-taught children and both groups of 11 -year-olds showed no significant difference between the two stimulus types.

Pseudohomophone sentence evaluation task. A three-way ANOVA was carried out on the percentage of correct responses in the pseudohomophone sentence evaluation task. See Table 2 for means and standard deviations. A main effect of age was found $[F(1,126)=$ $\left.37.05, M S_{\mathrm{e}}=252.25, p<.001\right]$, more accurate performance being obtained by the 11 -year-olds. There was a significant main effect of stimulus type $[F(1,126)=$ $\left.29.24, M S_{\mathrm{e}}=57.75, p<.001\right]$, but an interaction was found between age and stimulus type $[F(1,126)=12.91$, $\left.M S_{\mathrm{e}}=57.75, p<.001\right]$. No other effects were significant. In the analysis by items, there was also a significant

Table 2

Means and Standard Deviations for Percentage Correct Responses to Tasks in Experiment 1

\begin{tabular}{|c|c|c|c|c|c|c|c|c|}
\hline \multirow[b]{3}{*}{ Task } & \multicolumn{4}{|c|}{ 8-Year-Olds } & \multicolumn{4}{|c|}{ 11-Year-Olds } \\
\hline & \multicolumn{2}{|c|}{ Phonics } & \multicolumn{2}{|c|}{ Nonphonics } & \multicolumn{2}{|c|}{ Phonics } & \multicolumn{2}{|c|}{ Nonphonics } \\
\hline & $M$ & $S D$ & $M$ & $S D$ & $\bar{M}$ & $S D$ & $M$ & $S D$ \\
\hline \multicolumn{9}{|l|}{ Lexical decision } \\
\hline Pseudohomophones & 80.3 & 15.5 & 87.8 & 11.8 & 94.1 & 7.2 & 94.6 & 5.7 \\
\hline Control nonwords & 90.5 & 10.6 & 90.5 & 7.5 & 94.7 & 5.9 & 95.9 & 7.1 \\
\hline \multicolumn{9}{|l|}{$\begin{array}{l}\text { Pseudohomophone } \\
\text { sentence evaluation }\end{array}$} \\
\hline With pseudohomophone & 76.2 & 18.8 & 79.0 & 17.4 & 90.9 & 9.4 & 95.1 & 7.0 \\
\hline With control nonword & 84.2 & 15.9 & 88.0 & 13.5 & 94.7 & 7.0 & 94.7 & 5.7 \\
\hline \multicolumn{9}{|l|}{$\begin{array}{l}\text { Homophone sentence } \\
\text { evaluation }\end{array}$} \\
\hline With homophone & 57.8 & 14.9 & 59.1 & 14.4 & 66.9 & 15.3 & 75.0 & 16.4 \\
\hline With control word & 83.6 & 14.2 & 82.0 & 13.6 & 90.3 & 8.0 & 91.8 & 6.9 \\
\hline \multicolumn{9}{|l|}{ Word-meaning control } \\
\hline Homophones & 71.6 & 14.4 & 74.7 & 16.4 & 86.5 & 8.6 & 90.1 & 9.6 \\
\hline Control words & 77.8 & 14.8 & 76.2 & 15.0 & 90.3 & 9.2 & 91.0 & 6.7 \\
\hline
\end{tabular}


interaction between age and stimulus type $[F(1,38)=$ $\left.5.68, M S_{\mathrm{e}}=77.80, p<.025\right]$. Tests of simple main effects (planned comparisons) showed that both phonics and nonphonics groups of 8-year-olds were less accurate at evaluating the sentences with a pseudohomophone than at evaluating those with a matched control nonword. For the phonics-taught 8-year-olds, the simple main effect was significant $[t(126)=4.08, p<.001$, in the analysis by subjects; $t(38)=5.10, p<.001$, in the analysis by items]. For the nonphonics-taught 8 -yearolds, the effect was also significant $[t(126)=4.59, p<$ .001 , by subjects; $t(38)=5.83, p<.001$, by items]. The phonics-taught 11 -year-olds also showed a significant difference in the same direction $[t(126)=2.09, p<.05$, by subjects; $t(38)=2.55, p<.05$, by items]. The difference for the nonphonics-taught 11 -year-olds was not significant.

Homophone sentence evaluation and wordmeaning control tasks. A three-way analysis of covariance (ANCOVA) was carried out on the percentage of correct responses in the homophone sentence evaluation task. The intention of the covariate was to control for any differences between the subject groups in any homophony effect in the knowledge of the print forms and meanings of the homophones and control items. Homophony effects in the control task were very small compared with the effects in the homophone sentence evaluation task. Nevertheless, the control variable was included as a covariate for a more precise analysis of the group differences in the homophone sentence evaluation task. See Table 2 for means and standard deviations. With this covariance adjustment, a main effect of age was obtained $\left[F(1,125)=7.14, M S_{\mathrm{e}}=208.00, p<.001\right]$, with more accurate performance in the homophone sentence evaluation task by the 11 -year-olds. There was a main effect of stimulus type $\left[F(1,125)=228.36, M S_{\mathrm{e}}=\right.$ $121.78, p<.001]$, less accurate performance being obtained when evaluating the sentences with homophones than when evaluating the matched sentences in which the critical word was a control for visual similarity (to the unpresented homophone mate). No other main effects or interactions were significant. A covariance analysis with items as a random variate gave the same significant main effects [for age, $F(1,27)=9.22, M S_{\mathrm{e}}=$ $124.04, p<.01$; for stimulus type, $F(1,27)=8.23$, $\left.M S_{\mathrm{e}}=1,538.41, p<.01\right]$. There were no other significant effects. These results showed that there was a homophone effect in the sentence evaluation task after controlling for variation in knowledge of identity and meanings of the homophones and controls items. The effect did not vary between the phonics and nonphonics groups.

A parallel three-way ANOVA by subjects was carried out on the percentage of correct responses to the wordmeaning control task, which was used as the covariate in the above analysis. A main effect of age was obtained $\left[F(1,126)=58.70, M S_{\mathrm{e}}=228.89, p<.001\right]$, with more accurate performance by the 11 -year-olds. There was a main effect of stimulus type $\left[F(1,126)=10.11, M S_{\mathrm{e}}=\right.$ $62.67, p<.01]$, less accurate performance being ob- tained in identifying the meanings of the homophones than in identifying the meanings of the control words. However, this was qualified by a marginally significant interaction between subject groups and stimulus type $\left[F(1,126)=3.64, M S_{\mathrm{e}}=62.67, p=.06\right]$, indicating that the phonics-taught children had more difficulty than did the nonphonics-taught children in identifying the meanings of homophones, relative to control words. No other main effects or interactions were significant. An ANOVA by items gave a similar main effect of age $\left[F(1,28)=49.16, M S_{\mathrm{e}}=125.00, p<.001\right]$, but the main effect of stimulus type was not significant. As in the analysis by subjects, there was a marginally significant interaction between subject groups and stimulus type $\left[F(1,28)=3.85, M S_{\mathrm{e}}=40.45, p=.06\right]$. There were no other significant main effects or interactions in the analysis by items. The obtained marginally significant interactions with the subject groups justified the need to use the variable as a covariate in analyzing the group differences in the homophone sentence evaluation task.

\section{Discussion}

In the pseudohomophone sentence evaluation task, 8year-old learners erroneously accepted as making sense more of the sentences with a pseudohomophone than of those with a nonhomophoric control nonword. The two types of nonwords were matched on visual similarity to the real print words. The extent of this homophony effect did not vary according to the type of reading instruction the learners had received, although they showed marked variation in the extent of the homophony effect on the same nonwords in the lexical decision task. Those receiving explicit phonics instruction showed the effect in the lexical decision task, whereas those not receiving such instruction did not. These results indicate that, irrespective of the type of reading instruction children receive, they can make prelexical use of phonology in a task involving reading sentences for meaning. Why is this the case when, in the lexical decision task, which employs isolated words rather than sentences, learners not receiving phonics instruction showed no prelexical use of phonology? It appears that the inclusion of phonics as a component of reading instruction tends to increase the learner's attempts at obtaining reading responses by the prelexical use of phonology, even when such attempts are inappropriate, such as when making decisions on the lexical status of pseudohomophones (i.e., in the lexical decision task). Nevertheless, learners who have not received phonics instruction are able to make prelexical use of phonology when information from semantic and syntactic context is also available, as in reading sentences for meaning. They showed as many erroneous acceptances of the same pseudohomophones in sentences as did learners who had received phonics tuition. As expected, on the basis of the Patterson and Coltheart (1987) account, phonics instruction had no influence on the use of phonology in a homophone sentence evaluation task with embedded word homophones with irregular spelling-to-sound correspondences. 
The more skilled 11-year-old readers appeared to be at a ceiling performance level, $95 \%$ accuracy (19 of 20 items correct), in the lexical decision task. In the pseudohomophone sentence evaluation task, the same ceiling level was reached by the 11-year-old nonphonics-taught subjects; however, the phonics-taught 11-year-olds were not quite at ceiling, because they erroneously accepted more sentences with pseudohomophones than those with matched nonwords. Such an effect has previously been reported for 11-year-old subjects receiving phonics instruction (Johnston et al., 1987).

Experiment 1 has shown that learners can use phonology prelexically in a reading-for-meaning task and that it is a phenomenon not restricted to learners who have been exposed to a particular type of reading instruction. The results of Experiment 1 therefore support the conclusion of V. Coltheart et al. (1988), at least for responses to sentences containing a nonword. For more skilled readers, the results are not conclusive, since the relevant reading-for-meaning task is subject to a performance ceiling effect in such readers.

The findings also reveal a new phenomenon. Unlike learners who have had explicit phonics instruction, those who have not are apparently able to shut out the activation of phonology sufficiently to be unaffected by it when responding to items isolated from sentence context, as in the pseudohomophone lexical decision task. They apparently respond exclusively on the basis of stored orthographic lexical representations that do not involve phonology. However, when the same items are in meaningful sentence contexts, the same learners do not shut out the activation of phonology. The reason may be that the activation is necessarily involved in postlexical sentence processing. Once so activated, learners use the phonological information, at least in part, when responding to pseudohomophones in sentence contexts.

In Experiment 1, the intention was to examine the prelexical function of phonological codes in reading sentences for meaning. Phonology may also serve the function of access to lexical meanings or of postlexical sentence processing. Experiment 2 was conducted to examine such use by learners in similar reading-formeaning tasks but without the inclusion of nonwords. The intention was to distinguish between the function of phonology in access to lexical meanings and in postlexical sentence processing.

\section{EXPERIMENT 2}

The first objective of Experiment 2 was to examine the phonological influence of homophones when sentence processing is required and when it is not. This involved the determination of the readers' rejection rate of sentences with a semantically inappropriate homophone, as in Experiment 1 (e.g., "The son is shining in the sky"; i.e., homophone sentence evaluation task), and also their rejection rate of single words or short phrases as being similar in meaning to the same target homophones. In the latter task, for the target son, for example, subjects decided whether or not the members of the pair son-light express similar meanings (homophone semantic decision task). In each task, the phonological effects will be shown by lower rejection rates relative to visual similarity control items. If the phonological effect that occurs in the homophone sentence evaluation task is due exclusively to postlexical sentence processing, then no such effect would be expected in the homophone semantic decision task, which does not involve sentence processing. If, on the contrary, an effect is obtained in both tasks, then this would suggest that phonology has a function other than postlexical sentence processing. The function of access to lexical meanings is then a possible candidate, since this is required in both tasks.

Instances of correct rejection of homophones also need explanation. One explanation of correct responses is use of a direct-access route from the stored orthographic representation of the word to the lexical meaning (e.g., from the word son to the meaning "child"). With direct access, the meaning "light" would not be activated, because no phonological representation of sun would be involved, so the sentence "The son is shining in the sky" would be correctly rejected. This explanation would be compatible with several versions of dualroute theory (Baron, 1977; M. Coltheart, 1978, 1980; McCusker, Hillinger, \& Bias, 1981). There are alternative proposals that allow for more varied parallel processing procedures, including the three-route model of Patterson and Coltheart (1987), the Van Orden et al. (1990) covariant learning proposal, and the Jared and Seidenberg (1991) elaboration of the Seidenberg and McClelland (1989) model of direct and phonological routes to meaning. They allow not only for the possibility that lexical meanings can be accessed via the phonological representation of a print word but also for the possibility that, where multiple homophonic meanings are as a consequence activated, as with homophones, a spelling-check procedure can be used to determine which lexical meaning applies. For example, in the case of the print stimulus son, if the meanings "child" and "light" are both activated, the stored spellings associated with each lexical meaning could be checked against the print stimulus, a mismatch leading to a rejection of that associated meaning (see Figure 1). It is proposed that such spelling checks would be more effective the lower the threshold for activation of the mismatched orthographic representation (i.e., sun, activated by the lexical meaning "light") relative to the threshold for the matched orthographic representation (i.e., sON, activated by the other lexical meaning "child"). ${ }^{2}$ High word frequency would give some indication of low threshold. Hence, it would be expected that if such spelling checks can function in reading, then performance on the semantic decision task would be more accurate the greater the positive difference between (1) the word frequency of the corresponding homophone (not presented; e.g., sun, which is homophonic with the stimulus word son), and (2) the frequency of the stimulus word. If, also in the homophone sentence evaluation task, the phonological effect were at 
least partly due to processes of access of the lexical meaning of the homophone in the sentences, then similar relationships between performance and word frequency would be expected.

The spelling-check procedure described here is essentially the same as that proposed and examined by Van Orden (1987). It has also been extensively investigated by Jared and Seidenberg (1991) for skilled readers. As evidence, however, these investigators used individual frequency levels of the stimuli and corresponding homophone mates rather than the differences between these frequencies, as used here. These differences are seen as appropriate evidence, since the procedure postulated for the spelling-check procedure (Van Orden, 1987) gives precedence to the orthographic representation that is the most highly activated among the candidate representations, which will be the stimulus and its homophone mate.

Under the explanation that correct responses result only from direct-access connections between the stored orthographic representation and word meaning, no such frequency relationships would be expected involving the corresponding unpresented homophone mates. It would be expected that, because of the greater opportunity to acquire direct access connections to lexical meanings, high-frequency stimulus words would result in higher decision accuracy than would low-frequency words on both the homophone semantic decision task and the homophone sentence evaluation task. The second objective of Experiment 2 was to examine these relationships between homophone word frequency and item accuracy. It was not possible to manipulate word frequency as levels in an ANOVA design in these experiments because the set of irregular homophone words in the print vocabularies of learners is very small. The words used in the experiments exhaust nearly the entire set of suitable words that are homophonic in both Scottish and New Zealand
English and for which there are suitable words that can serve as controls for visual similarity.

\section{Method}

Subjects. The results of Experiment 1 showed that readers receiving each kind of instruction did not vary in the extent of the phonological effect in the homophone sentence evaluation task. Hence, in Experiment 2, the kind of instruction the readers received was not a variable. One hundred and eighty-two children ( 8 and 11 years old) were initially tested from the same schools in New Zealand employed in Experiment 1. Reading-attainment levels were assessed by the same test. Low-achievement and superior readers were excluded, as were non-Caucasian children. The subjects were selected to match the ages and reading-attainment levels in Experiment 1. The 8-year-old sample, comprising 14 girls and 17 boys, had a mean chronological age of 8.7 years $(S D=$ 0.31 ) and a mean reading age of 8.7 years $(S D=0.94)$. The 11 year-old sample, comprising 25 girls and 23 boys, had a mean chronological age of 11.7 years $(S D=0.27)$ and a mean reading age of 11.7 years $(S D=1.42)$.

Homophone sentence evaluation task. The homophone sentence evaluation task was the same as that in Experiment 1. The first section of the task was administered first in the testing session and the second section following administration of the test of reading attainment. The results of the word-meaning control task in Experiment 1 showed that for both age groups of New Zealand subjects, performance on the homophones and the visual similarity control words was closely matched, indicating equivalent levels of difficulty for identification of the print word meanings. Because the subjects for Experiment 2 were of closely similar ages and reading-attainment levels and were drawn from the same schools as those in Experiment 1, it was not considered necessary to repeat the word-meaning control task in this experiment.

Homophone semantic decision task. Each of the homophone and visual similarity control words from the preceding task were presented along with a word or short phrase. This represented the meaning for which the homophone or control word was inappropriate in the sentence of the evaluation task. For example, two corresponding items were:

$$
\begin{aligned}
& \text { son-light } \\
& \text { sure-light }
\end{aligned}
$$

Stimulus

Stored orthographic representations of words

Stored lexical phonological representation

Stored word meanings

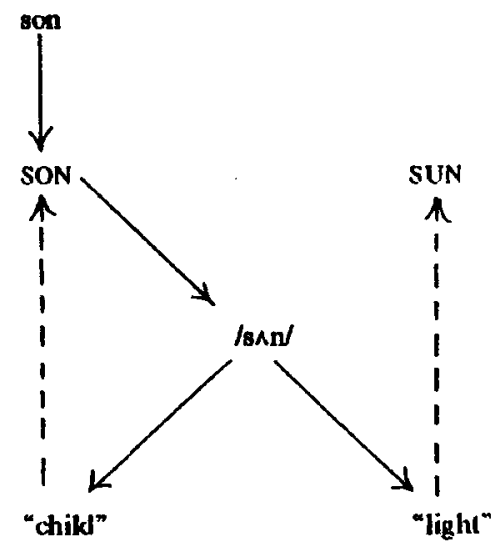

\section{Key: $\longrightarrow$ Trassfer of infonmation activated from the stimulus

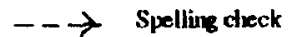

Figure 1. Example of postulated spelling-check procedure that can be used in word identification for reading. 
The subject ticked the item if a matching meaning was given or marked it with a cross if the meaning did not match. The purpose of the task was to examine homophony effects on access to lexical meanings of the target homophones when removed from their sentence contexts. For this reason, it differed in several respects from the semantic decision task employed by Van Orden (1987), Van Orden et al. (1988), and Jared and Seidenberg (1991). In their task, a decision was made on whether a word was an example of a previously named category.

There were 15 items for the homophones and 15 for the control words. They are listed in Appendix E. Thirty filler items with correct meanings were constructed. Sixteen of these comprised items that could be related in pairs (e.g., speed-go fast, speed-quick), and the remaining items were unrelated (e.g., grow-get bigger, discover-find). No more than three successive items were homophones or controls, and no more than three successive items were fillers. If one item of a related pair appeared in the first half of the 60 items, then the corresponding item appeared in the second half, and vice versa. Two versions were used, as in the preceding task.

The children were instructed that they were to decide whether the meanings given for each word were close or whether they were wrong. Four demonstration items were presented and, when a homophone item appeared in these, the experimenter said, "That sounds all right, but this word is spelt wrongly for that meaning. So it gets a cross." The children read silently and were told to do the task as accurately and as fast as they could.

\section{Results and Discussion}

Phonological effects of the tasks. A two-way (age $x$ stimulus type) ANCOVA was carried out on the percentage of correct responses in the homophone sentence evaluation task, controlling for any phonological effects in the homophone semantic decision task (as covariate). See Table 3 for means and standard deviations. With the covariate adjustment, the main effect of age was not significant $\left[F(1,76)=2.94, M S_{\mathrm{e}}=170.65, p>.05\right]$. There was a main effect of stimulus type $[F(1,76)=39.07$, $\left.M S_{\mathrm{e}}=85.32, p<.001\right]$, performance being less accurate in evaluation of sentences with homophones than in evaluation of the matched sentences with words controlling for visual similarity. This main effect accounted for $62 \%$ of the total within-subject adjusted variance, whereas it accounted for $92 \%$ of the total within-subject unadjusted variance. With the covariate adjustment, there was a significant interaction between age and stimulus type $\left[F(1,76)=12.12, M S_{\mathrm{e}}=85.32, p<.001\right]$. The adjusted mean percentage correct responses to sentences with homophones was $62 \%$ for 8 -year-olds and $72 \%$ for 11 year-olds, with the adjusted means for the control sentences being $88 \%$ for both age groups. However, in the covariance analysis by items (matched pairs of homophone and visual similarity control items), the interaction between age and stimulus type was not significant $\left[F(1,41)=2.76, M S_{\mathrm{e}}=117.90, p>.05\right]$. The main effect of age in this analysis by items was also not significant $\left[F(1,41)<1, M S_{\mathrm{e}}=117.90\right]$, but the main effect of stimulus type was $\left[F(1,41)=8.05, M S_{\mathrm{e}}=117.90, p<\right.$ .011 .

A two-way (age $\times$ stimulus type) ANOVA was conducted on the percentage of correct responses in the homophone semantic decision task, used as a covariate in the above analysis. See Table 3 for means and standard deviations. There was a main effect of stimulus type $\left[F(1,77)=119.23, M S_{\mathrm{e}}=70.66, p<.001\right]$, performance being less accurate in decisions on homophones than on the control words matched on visual similarity. The main effect of age was significant $[F(1,77)=35.60$, $M S_{\mathrm{e}}=209.76, p<.001$ ], performance being more accurate by the 11 -year-olds than by the 8 -year-olds. The interaction between age and stimulus type was not significant. In the analysis by items (matched pairs), there were significant main effects of stimulus type $[F(1,42)=$ $\left.14.45, M S_{\mathrm{e}}=235.57, p<.001\right]$ and age $[F(1,42)=$ $\left.12.72, M S_{\mathrm{e}}=235.57, p<.001\right]$. The interaction was not significant.

There were large phonological effects in both the homophone semantic decision and homophone sentence evaluation tasks (Table 3 ). A covariance analysis shows that, if a linear relationship is assumed, the homophony effect of the semantic decision task did not fully account for that in the homophone sentence evaluation task. Whether or not the assumption of this relationship is accepted, it is clear from the large homophony effect in the semantic decision task that these phonological effects are not due exclusively to postlexical sentence processing (for segments larger than a short phrase). Hence, other functions of phonology that belong to the semantic decision task, such as access to lexical meanings, are not excluded by the results. Further evidence was obtained by examining the relationships between homophone word frequency and item accuracy.

Homophone frequency and item accuracy. To provide a measure amenable to linear correlation statistics, a logarithmic transformation, $\log _{10}(f+10)$, of the raw word frequencies, $f$, was made. For each item, a frequency difference was calculated by subtracting the transformed frequency measure for the stimulus word (e.g., son) from that for the corresponding appropriate homophone mate (e.g., sun, not presented). This difference variable was calculated for each of the homophone words $(M=-0.004, S D=0.89)$ and for the visual similarity control words $(M=0.084, S D=0.76)$ of the homophone semantic decision task. Both means were close to zero and, in each case, there were seven negative and eight positive values. The two components of this relative frequency variable were uncorrelated for the homophone words ( $r=.04$ over items). The means of these

Table 3

Means and Standard Deviations for Percentage Correct Responses to Tasks in Experiment 2

\begin{tabular}{|c|c|c|c|c|}
\hline \multirow[b]{2}{*}{ Task } & \multicolumn{2}{|c|}{ 8-Year-Olds } & \multicolumn{2}{|c|}{11 -Year-Olds } \\
\hline & $M$ & $S D$ & $M$ & $S D$ \\
\hline \multicolumn{5}{|l|}{$\begin{array}{l}\text { Homophone } \\
\text { sentence evaluation }\end{array}$} \\
\hline With homophone & 57.4 & 14.7 & 76.1 & 16.8 \\
\hline With control word & 84.5 & 11.7 & 91.5 & 7.1 \\
\hline \multicolumn{5}{|l|}{$\begin{array}{l}\text { Homophone } \\
\text { semantic decision }\end{array}$} \\
\hline Homophones & 65.8 & 14.4 & 81.3 & 13.3 \\
\hline Controls & 82.2 & 13.3 & 94.9 & 6.2 \\
\hline
\end{tabular}


$\log$ frequencies did not differ, being $1.81(S D=0.57)$ for the homophone stimulus words and $1.82(S D=0.72)$ for the corresponding (unpresented) homophone mates. The mean for the control stimulus words was $1.73(S D=$ $0.67)$, which was not significantly different from that for the homophone stimulus words $[t(14)=0.41]$. The same frequency variables also applied to the items of the homophone sentence evaluation task. Results on this task were also available from Experiment 1.

Item response accuracy was measured by the unweighted average over age groups (and also national groups in Experiment 1) of the percentage of subjects in each group correctly responding to the item. In Experiment 1 , the means and standard deviations calculated over items for percentage response accuracy on the homophone sentence evaluation task were $64.6 \%(S D=$ $25.5)$ for the homophone sentences and $86.4 \%(S D=$ 11.8) for the controls. In Experiment 2, they were $66.7 \%$ $(S D=25.3)$ and $88.1 \%(S D=13.5)$, respectively. In the homophone semantic decision task of Experiment 2, they were $73.5 \%(S D=20.9)$ and $88.6 \%(S D=10.5)$. These item response accuracy measures were correlated with the frequency variables of the items. The results are given in Table 4.

As in the previously reported findings on learners' responses to the homophone sentence evaluation task (V. Coltheart et al., 1988), the correlation between log frequency of the stimulus homophone and item accuracy was nonsignificant. Relative frequencies were not reported in that study. There are no previous results on the homophone semantic decision task used here. The only obtained correlations having significant nonzero values are those between homophone item accuracy and the relative frequency variable, calculated for the difference in frequency between the corresponding homophone mate (not presented) and the stimulus homophone $(a-b$ in Table 4). These were positive correlations and exceeded .50 for the sentence evaluation task as well as the homophone semantic decision task. Thus, the higher the frequency of the unpresented homophone mate relative to the frequency of the stimulus homophone, the less likely is the stimulus to be confused with its homophonic mate. The respective correlations for the visual similarity control items were close to zero. These correlation results for the control items in both tasks are particularly important because they make improbable an alternative interpretation of the results for the experimental homophone items. The correlation results for the experimental items cannot be due simply to the readers rejecting print stimuli with which they are unfamiliar - that is, rejecting low-frequency stimulus words and, hence, being particularly accurate on these without engaging in a spellingcheck procedure. If this were the case, a similar result should have occurred for the control items, since these do not differ from the homophone items in mean log frequency, and the variance of the controls is at least as large. Furthermore, in the word-meaning control task of Experiment 1, an analysis over items showed that homophone stimulus and control words were at equivalent levels of difficulty for the readers' identification of print word meanings. Mean accuracy was not significantly different $[t(14)=0.65]$.

Moreover, the experimental correlation results are not due simply to the subjects accepting a stimulus word because they are unfamiliar with the print form of what would be the appropriate word (homophone mate) instead of the stimulus. The prediction from the spellingcheck procedure is that low accuracy will not generally occur in such cases but only when the experimental stimulus word is of higher frequency than the unpresented homophone mate. The correlation results are consistent with this prediction. Furthermore, the prediction also is that low accuracy will not generally occur when the experimental stimulus words are of high frequency. If the reader were simply accepting these as familiar print stimuli and not engaging in a spelling-check process, then the correlation results obtained for the experimental items should also be apparent in the control items. Although the variance for accuracy on the control items is less than that for the experimental items, this

Table 4

Linear Product-Moment Correlations Between Frequency Variables and Average Percentage Accuracy of Task Items, Combined Across Groups

\begin{tabular}{|c|c|c|c|}
\hline \multirow[b]{2}{*}{ Task Items } & \multicolumn{3}{|c|}{ Frequency Variables } \\
\hline & $\begin{array}{c}\text { Corresponding Homophone } \\
\qquad a \\
\end{array}$ & $\begin{array}{l}\text { Stimulus Homophone/Control } \\
b\end{array}$ & $a-b$ \\
\hline \multicolumn{4}{|c|}{ Homophone Sentence Evaluation } \\
\hline \multicolumn{4}{|l|}{ Experiment 1} \\
\hline Homophone & .31 & -.45 & $.53^{*}$ \\
\hline Control & .12 & .06 & .07 \\
\hline \multicolumn{4}{|l|}{ Experiment 2} \\
\hline Homophone & .36 & -.40 & $.53 *$ \\
\hline Control & .21 & .14 & .08 \\
\hline \multicolumn{4}{|c|}{ Homophone Semantic Decision } \\
\hline \multicolumn{4}{|l|}{ Experiment 2} \\
\hline Homophone & .33 & -43 & $.54^{*}$ \\
\hline Control & .30 & .23 & .08 \\
\hline
\end{tabular}


does not account for the near-zero correlations for the controls (Table 4). The three correlations for the experimental items when adjusted to the lower variance of the controls are in the range of .28 to .32 , not the .07 and .08 obtained for the controls. The obtained effects would seem to be explainable only by some process that is specific to phonological representations for the words. The spelling-check procedure is such a process, and it also predicts the obtained pattern of relationships between performance and relative word frequencies in both the homophone sentence evaluation task and the semantic decision task. The several plausible alternative response procedures considered above do not predict the obtained pattern of relationships, nor are they procedures specific to the phonological representations of the words.

The question remains whether, as expected, phonology serves functions that include accessing lexical meanings. The alternative possibility is that phonology exclusively serves postlexical functions. There are results that render this alternative improbable in the homophone semantic decision task. If subjects use phonology for access to lexical meanings, then in order to enable them to distinguish between several activated homophonic meanings, it is expected that a spelling-check procedure is used. Homophonic print stimuli that are visually very similar to their unpresented homophonic mates would be more likely to fail to be detected as mismatches in the spelling-check procedure than would stimuli that are visually less similar. Hence, it would be expected that there would be a significant negative correlation between such visual similarity (Weber index) and item accuracy. This was the result obtained in the homophone semantic decision task $(r=-.58$ over items, $p<.025)$. This influence of visual similarity indicates involvement of orthographic representations of words and, hence, of lexical access. Moreover, it is an effect specific to the homophone stimuli, as indicated by the fact that it did not occur for the visual control items $(r=+.20, p>.05)$, for the correlation between control item accuracy and visual similarity (between the control word and the unpresented homophonic mate of the matched homophone). It should be noted that the means and variances of visual similarity are matched between homophone and control words (see Experiment 1 for values). The influence of visual similarity in the homophone items is an effect involving phonology in the processes of access to lexical meanings of print words. In contrast to performance on the homophone semantic decision task, performance on the homophone sentence evaluation task is expected to be influenced by postlexical functions of sentence processing as well as lexical access functions of phonology. The large component of a postlexical sentence processing function in the homophone sentence evaluation task could be expected to weaken the negative correlation between visual similarity and item accuracy, since accuracy would show the influence of postlexical sentence processing as well as the influence of processes of lexical access that are affected by visual similarity. Such a result was obtained. In the homophone sentence evaluation task, $r=-.42, p>.05$, for the correlation between visual similarity and item accuracy. For the controls, $r=+.24$. For the same task in Experiment $1, r=-.42$, for homophones, and $r=$ +.02 , for controls.

The complete set of obtained relationships are consistent with those expected if lexical meanings are at times accessed via phonology, but, where multiple homophonic meanings are activated, a spelling-check procedure is applied by the learner. The results are not consistent with the account that correct responses to print word homophones were exclusively due to direct access of the word meaning from the activated orthographic representation of the word. If this were the case, a significant positive correlation between homophone stimulus frequency and item accuracy would have been expected in the homophone semantic decision task. The obtained correlation was not significant (Table 4). Moreover, the significant relative word-frequency effect and visual similarity effect, which were specific to the use of phonology, are not compatible with the exclusive direct-access account.

\section{GENERAL DISCUSSION}

A conclusion of Experiment 1 is that, by the time children are 8 years old, they show the effects of the use of phonology in sentence-reading tasks, regardless of whether their reading instruction has included explicit phonics tuition that is directed toward the prelexical use of phonology. Although V. Coltheart and Laxon (1990) did not have a comparison of 8-year-olds taught with and without phonics, our findings are consistent with their results, insofar as their 7-and 8-year-old subjects who were taught without explicit phonics showed the effects of prelexical as well as lexical or postlexical functions of phonology. However, in their examination of three groups of 6-year-old subjects, those that received teaching without an emphasis on explicit phonics tuition failed to show the effect of prelexical use of phonology, although they did show the other effects. The 6-yearolds exposed to phonics, like the older children, showed both kinds of effects. In view of these results and those of Experiment 1, it appears that, in children older than 6 years, the effects of phonology in reading sentences for meaning are independent of exposure to phonics instruction. Such is not the case, however, in reading tasks involving items out of sentence context. Although not examined by V. Coltheart and Laxon (1990), such a task was included in the present study. In Experiment 1, the 8-year-old learners with phonics instruction showed the influence of the prelexical use of phonology in the pseudohomophone lexical decision task, whereas those without phonics did not show an influence. In this lexical decision task, the prelexical function of phonology is unnecessary and indeed inappropriate. Hence, the learners without phonics showed a more mature level of performance on the task than did those taught explicit phonics. This was not simply due to the children without phonics being unable to use phonology prelexically. 
They did show some such use in responding to the same pseudohomophone and control nonword items when embedded in sentences (Experiment 1). Although information from the sentence context was available to contribute to reading responses in this task, this was not sufficient by itself to explain the phonological effect, since the control nonwords, which were matched for visual similarity to words, were also embedded in such contexts. In learners, the prelexical use of phonology in responding to sentences with an embedded pseudohomophone appears to be a phenomenon not restricted to those exposed to a particular method of reading instruction. These new observations suggest that, for all learners, phonology becomes a necessary component in sentence processing; they cannot shut off the influence. However, learners who receive reading instruction without explicit phonics are apparently able to shut off the influence of phonology in the pseudohomophone lexical decision task in which items are presented out of sentence context and respond exclusively on the basis of stored orthographic lexical representations that do not involve phonology. For these learners, the prelexical use of phonology is under strategic control. Although phonological information is not appropriate to accuracy in this task, the learners receiving explicit phonics did not shut off the influence of phonology. For these children, who were systematically taught a strategy of prelexical use of phonology, there was apparently a reluctance to shut down such a strategy even when it was not appropriate for the task.

There is, however, another potential interpretation of the results that needs to be considered. The spelling-check procedure that has been described for the sentence evaluation task could also operate in the pseudohomophone lexical decision task. On the pseudohomophone items, a lexical meaning can be activated via the phonological representation of the word homophonic with the pseudohomophone. This activated meaning can then be the basis of a spelling check if the stored spelling associated with that lexical meaning is checked against the stimulus pseudohomophone. This procedure, if used, would facilitate rejection of pseudohomophones but would not have any direct effect on responses to the visual similarity control nonwords. The result would be a reduction in the false positive responses to pseudohomophones. This would suggest that the subjects who received no explicit phonics instruction might be superior to the phonicstrained subjects at using a spelling-check procedure, which would reduce the false positive errors that would otherwise arise from exclusive prelexical use of phonology in this task. However, if the nonphonics subjects were more generally inclined to use (or were more proficient at using) a spelling-check procedure, then they would be expected also to show an advantage over the phonics subjects in terms of lower false positive responses in both the homophone and the pseudohomophone sentence evaluation tasks. The results from Experiment 1 for both sentence evaluation tasks, however, showed the same level of false positive responses, rela- tive to visual similarity controls, for the learners with and without explicit phonics instruction. There were no significant subject group differences. It may be argued, though, that the 8-year-old phonics subjects made use of a spelling-check procedure in both sentence evaluation tasks but not in the lexical decision task. This seems improbable if it is considered that a spelling-check or similar verification procedure is not completely automatic and thus requires attentional resources (Stone \& Van Orden, $1989,1993)$. The sentence evaluation tasks are more complex than the lexical decision task and presumably have more overall attentional demands arising from sentence processing. Hence, greater attentional resources would be available for using a spelling-check procedure in the lexical decision task than in the sentence evaluation tasks. The interpretation preferred here for the effect of phonics reading instruction on the pseudohomophone lexical decision task performance of the 8-year-olds is more straightforward. Those learners receiving explicit phonics instruction did not shut down a taught strategy for the prelexical use of phonology when it was inappropriate to the task, whereas those without this instruction had acquired some such strategy but more readily shut it down when inappropriate to the task.

In a theoretical account of any cognitive skill, one of the important issues is how the acquired skill is linked with existing knowledge and skills. When the child is acquiring orthographic representations of words, the meanings of most of these words will be available to the child in previously stored knowledge. An important question is how these word meanings are accessed by the new skill of reading. What permanent links are formed between the newly acquired and stored orthographic representation of words and existing stored representations of word meanings? (Procedures that may be used temporarily to assist in forming such links-for example, by prelexical use of phonology - are another matter.) There are two principal possibilities. The first is that a direct pathway is formed between the new orthographic representation of the print word and the existing representations of the meaning(s) of the word, bypassing connections with the existing representation of phonology of the word. The second possibility is that access to word meaning is made via the existing phonological representation of word or morpheme, and this is then the point of access of the new skill of print word identification to existing knowledge of meanings of words. It may remain so as the skill develops. The evidence presented here suggests that the second possibility operates at least some of the time.

Our results show that, at least on some occasions, in judging the meaning of sentences children access phonology prior to activating the meaning of a word. There is evidence that when multiple meanings are activated by the phonology common to pairs of homophonic words, a spelling-check procedure is activated. The proportion of errors that occur on the occasions when the connection to meaning via phonology is activated would be reduced by the spelling-check procedure, leading to 
the observed correlations between relative word frequency of presented and unpresented homophone mates and accuracy of performance on items of the sentence evaluation and the semantic decision tasks. Where the inappropriate presented homophone is of lower frequency than its unpresented but appropriate homophone mate, the child is better able to correctly reject the sentence and make a correct semantic decision. It thus appears that phonologically activated representations and the subsequent spelling-check procedure are involved in accessing lexical meanings of homophones in the sentence evaluation and semantic decision tasks. Nevertheless, because not all relevant variance has been fully accounted for in the present experiments, the results do not exclude the likelihood that a direct connection to meaning may also operate in parallel with these phonological and spelling-check pathways

Our finding that, on some occasions, learners access phonology prior to activating the meanings of words is compatible with the three-route account of Patterson and Coltheart (1987), the Van Orden et al. (1990) covariant learning proposal, and the Jared and Seidenberg (1991) account. Although in the first account the phonological representations that are activated prior to lexical meaning can be either "assembled" or "addressed" phonology, the conceptions of print-to-sound connections in the other accounts do not provide the distinction of exclusively "addressed" phonology. The present data do not adjudicate on this point. While words with irregular spelling-to-sound correspondences were employed in both experiments, results with such words can be claimed not to exclude the influence of the prelexical function of phonology (Van Orden et al., 1990).

The spelling-check procedure proposed here is essentially the verification process proposed by Van Orden (1987) and derived from Rubenstein, Lewis, and Rubenstein (1971), in which a phonologically activated candidate set of lexical meaning representations is subjected to checking processes based on visual-orthographic codes. Jared and Seidenberg (1991) concluded that such a spelling check is not obligatory in the process of word identification of nonhomophones nor even all cases of homophony. They provided evidence consistent with the use of such a verification process by skilled adult readers, but only for their responses to low-frequency homophones when the task requires rejection of stimulus meanings. The present results do not discriminate on this question. However, Experiment 2 has provided new observations that learners, when they make correct responses to homophones, are not doing so exclusively by direct connections between orthography and lexical meanings. The results show they make some considerable use of phonology for access to lexical meanings, insofar as this use requires a spelling-check procedure to obtain accurate responses. It has thus been shown that success in use of such a spelling-check procedure is not restricted to the skilled reader.

Nevertheless, the phonological effects in sentence evaluations found in Experiment 2 probably cannot be entirely accounted for in terms of processes for accessing lexical meanings. There was a larger phonological effect in performance on the sentence evaluation task than on the semantic decision task, which did not involve sentence processing. This difference possibly reflects the operation of postlexical phonological short-term storage. As the homophone item is read, orthographic, phonological, and semantic information would be activated. This information would be placed in temporary storage during reading of the sentence but, on some occasions, the orthographic and semantic information would decay before the phonological. Hence, some sentences would be accepted as correct because of the way they sounded. It can be concluded that (1) in silent reading of sentences for meaning, learners 8 years of age and older show effects of phonology, (2) these effects are found independently of how subjects have been taught to read, and (3) the effects are indicative of some use of phonology in accessing lexical meanings as well as in any temporary postlexical storage for sentence processing. Moreover, learners as young as 8 years are effective in using a spellingcheck procedure to facilitate access to lexical meanings of print words.

There are some implications of the findings for reading instruction. The results have indicated that phonology is used by learners during reading to access lexical meanings, in addition to any use of direct pathways that exclude phonology. Hence, an instuctional program may be unrealistic if one of its aims is to have readers accessing lexical meanings exclusively by the direct-access pathway between stored lexical orthographic representations and lexical meanings. It is suggested that allowance should be made for the involvement of phonology in the pathway between lexical orthographic representations and lexical meanings, as well as for the direct-access pathway and the prelexical print-to-sound pathway.

\section{REFERENCES}

BARON, J. (1973). Phonemic stage not necessary for reading. Quarterly Journal of Experimental Psychology, 25, 24l-246.

BARON, J. (1977). Mechanisms for pronouncing printed words: Use and acquisition. In D. LaBerge \& S. J. Samuels (Eds.), Basic processes in reading: Perception and comprehension (pp. 175-216). Hillsdale, NJ: Erlbaum

Besner, D. (1987). Phonology, lexical access in reading, and articulatory suppression: A critical review. Quarterly Journal of Experimental Psychology, 39A, 467-478

Brimer, M. A., \& DUnn, L. M. (1968). English picture vocabulary test 2. Newnham, Glasgow: Educational Evaluation.

Carroll, J. B., Davies, P., \& Richman, B. (1971). The American Heritage word frequency book. Boston: Houghton Mifflin.

Coltheart, M. (1978). Lexical access in simple reading tasks. In G. Underwood (Ed.), Strategies of information processing (pp. 151216). London: Academic Press.

Coltheart, M. (1980). Reading, phonological recoding, and deep dyslexia. In M. Coltheart, K. Patterson, \& J. C. Marshall (Eds.), Deep dyslexia (pp. 197-226). London: Routledge \& Kegan Paul. Coltheart, M., Curtis, B., Atkins, P., \& Haller, M. (1993). Models of reading aloud: Dual-route and parallel-distributed processing approaches. Psvchological Review, 100, 589-608.

Coltheart, V., Avons, S. E., Masterson, J., \& Laxon, V. J. (1991). The role of assembled phonology in reading comprehension. Memory \& Cognition, 19, 387-400. 
Coltheart, V., Avons, S. E., \& Trollope, J. (1990). Articulatory suppression and phonological codes in reading for meaning. Quarterly Journal of Experimental Psychology, 42A, 375-399.

Coltheart, V., \& Laxon, V. J. (1990). The development of phonological mediation in reading comprehension. Language \& Cognitive Processes, 5, 81-104.

Coltheart, V., Laxon, V. [J.], Rickard, M., \& Elton, C. (1988). Phonological recoding in reading for meaning by adults and children. Journal of Experimental Psychology: Learning. Memory, \& Cognition, 14, 387-397.

Daneman, M., \& Stainton, M. (199l). Phonological recoding in silent reading. Journal of Experimental Psvchologv: Learning. Memory, \& Cognition, 17, 618-632.

Doctor, E. A., \& ColthearT, M. (1980). Children's use of phonological encoding when reading for meaning. Memory \& Cognition, $\mathbf{8}$, 195-209.

FranCE, N. (1981). The primary reading test (rev. ed.). Windsor, Berkshire, U.K.: NFER-Nelson.

Holligan, C., \& Johnston, R. S. (1988). The use of phonological information by good and poor readers in memory and reading tasks. Memory \& Cognition, 16, 522-532.

Jared, D., \& Seidenberg, M. S. (1991). Does word identification proceed from spelling to sound to meaning? Journal of Experimental Psvchology: General, 120, 358-394.

Johnston, R. S., RugG, M. D., \& Scott, T. (1987). The influence of phonology on good and poor readers when reading for meaning. Journal of Memory \& Language, 26, 57-68.

Johnston, R. S., RugG, M. D., \& ScotT, T. (1988). Pseudohomophone effects in 8 and 11 year old good and poor readers. Journal of Research in Reading, 11, 110-119.

Johnston, R. S., \& ThOMPSON, G. B. (1989). Is dependence on phonological information in children's reading a product of instructional approach? Journal of Experimental Child Psychology, 48, 131-145.

KLEIMAN, G. M. (1975). Speech recoding in reading. Journal of Verbal Learning \& Verbal Behavior, 14, 323-339.

Liberman, I., Liberman, A. M., Mattingly, I., \& Shankweiler, D. (1980). Orthography and the beginning reader. In J. F. Kavanagh \& R. L. Venezky (Eds.), Orhograph, reading, and dislexia (pp. 137 153). Baltimore: University Park Press.

McCusker, L. X., Hil..inger, M. L., \& Bias, R. G. (1981). Phonological recoding and reading. Psychological Bulletin, 89, 217-245.

Patterson, K., \& Colthi.arT, V. (1987). Phonological processes in reading: A tutorial review. In $\mathrm{M}$. Coltheart (Ed.), Attention and performance XII: The psichologr of reading (pp. 421-447). Hillsdale, NJ: Erlbaum

Rubenstein, H., Lewis, S. S., \& Rubenstein, M. A. (1971). Evidence for phonemic recoding in visual word recognition. Journal of Verbal Learning \& Verhal Behavior, 10, 645-657.

SeidenberG, M. S., \& Mc Clel.land, J. L. (1989). A distributed, developmental model of word recognition and naming. Psychological Review, 96, 523-568

Stone, G. O., \& VAN OrdfN, G. C. (1989). Are words represented by nodes? Memory \& Cognition, 17, 511-524.
Stone, G. O., \& Van Orden, G. C. (1993). Strategic control of processing in word recognition. Journal of Experimental Psychology: Human Perception \& Performance, 19, 744-774.

TAFT, M. (1982). An alternative to grapheme-phoneme conversion rules? Memory \& Cognition, 10, 465-474.

THOMPSON, G. B. (1993). Reading instruction for the initial years in New Zealand schools. In G. B. Thompson, W. E. Tunmer, \& T. Nicholson (Eds.), Reading acquisition processes (pp. 148-154). Clevedon, U.K.: Multilingual Matters.

Thompson, G. B., \& FletCher-Flinn, C. M. (1993). A theory of knowledge sources and procedures for reading acquisition. In G. B. Thompson, W. E. Tunmer, \& T. Nicholson (Eds.), Reading acquisition processes (pp. 20-73). Clevedon, U.K.: Multilingual Matters.

ThOMPSON, G. B., \& JOHNSTON, R. S. (1993). The effects of type of instruction on processes of reading acquisition. In G. B. Thompson, W. E. Tunmer, \& T. Nicholson (Eds.), Reading acquisition processes (pp. 74-90). Clevedon, U.K.: Multilingual Matters.

Treiman, R., Freyd, J. J. \& Baron, J. (1983). Phonological recoding and use of spelling-sound rules in reading of sentences. Journal of Verbal Learning \& Verbal Behavior, 22, 682-700.

VAN ORDEN, G. C. (1987). A ROWS is a ROSE: Spelling, sound, and meaning. Memory \& Cognition, 15, 181-198.

VAN ORden, G. C., Johnston, J. C., \& Hale, B. L. (1988). Word identification in reading proceeds from spelling to sound to meaning. Journal of Experimental Psychology: Learning, Memory, \& Cognition, 14, 371-386.

Van Orden, G. C., Pennington, B. F., \& Stone, G. O. (1990). Word identification in reading and the promise of subsymbolic psycholinguistics. Psychological Review, 97, 488-522.

WEBER, R. (1970). A linguistic analysis of first-grade reading errors. Reading Research Quarterly, 5, 427-451.

\section{NOTES}

1. In a preliminary experiment on the pseudohomophone lexical decision task (Experiment 1), both accuracy and reaction times were recorded for phonics-taught British 8-year-olds $(n=20), 11$-year-olds $(n=20)$, and adults $(n=18)$. Pseudohomophones were rejected as quickly as visual control nonwords, there being no main effect in the reaction times for stimulus type $(F<1)$, and no interaction between subject group and stimulus type $(F<1)$. However, as far as accuracy was concerned, there was an interaction between groups and stimulus type $\left[F(2,55)=5.10, M S_{\mathrm{e}}=412.34, p<.01\right]$ : Newman-Keuls tests showed that only the 8 -year-olds made more errors to pseudohomophones than to visual control nonwords.

2 . There may also be cases in which there is no adequate orthographic representation for the stimulus word (e.g., son), but, in spite of the stimulus having irregular spelling-to-sound correspondence, prelexical phonological mediation may enable activation of the appropriate stored lexical phonological representation. At the same time, however, there is in such cases an adequate orthographic representation available for the mismatched word (e.g., sun). The same predictions concerning relative word frequencies would apply to these cases. 


\begin{tabular}{|c|c|}
\hline \multicolumn{2}{|c|}{$\begin{array}{c}\text { APPENDIX A } \\
\begin{array}{l}\text { Pseudohomophone and Matched Control Nonword Items } \\
\text { in the Pseudohomophone Lexical Decision Task }\end{array}\end{array}$} \\
\hline Pseudohomophones & Control Nonwords \\
\hline $\begin{array}{l}\text { loe } \\
\text { hoase } \\
\text { wosp } \\
\text { moove } \\
\text { gon } \\
\text { luv } \\
\text { poast } \\
\text { hoam } \\
\text { wotch } \\
\text { boath } \\
\text { teech } \\
\text { gole } \\
\text { bild } \\
\text { bloan } \\
\text { blud } \\
\text { wosh } \\
\text { oan } \\
\text { wurd } \\
\text { tutch } \\
\text { coff }\end{array}$ & $\begin{array}{l}\text { coe } \\
\text { loase } \\
\text { gosp } \\
\text { doove } \\
\text { bon } \\
\text { druv } \\
\text { loast } \\
\text { soam } \\
\text { cotch } \\
\text { moath } \\
\text { spreed } \\
\text { brode } \\
\text { brise } \\
\text { doan } \\
\text { blum } \\
\text { mosh } \\
\text { goan } \\
\text { lurd } \\
\text { cutch } \\
\text { boff } \\
\end{array}$ \\
\hline \multicolumn{2}{|c|}{$\begin{array}{c}\text { APPENDIX B } \\
\text { Pseudohomophone Sentences and Matched Control Nonword Sentences } \\
\text { in the Pseudohomophone Sentence Evaluation Task }\end{array}$} \\
\hline Sentences With a Pseudohomophone & Sentences With a Control Nonword \\
\hline $\begin{array}{l}\text { The sun is loe in the sky. } \\
\text { The hoase was turned on. } \\
\text { That wosp might try to sting you. } \\
\text { Can I moove your books? } \\
\text { All the sweets have gon. } \\
\text { Do you luv your brother? } \\
\text { Can you poast this letter? } \\
\text { This is my hoam. } \\
\text { He has broken his wotch. } \\
\text { Boath of you are to blame. } \\
\text { Can you teech me how to swim? } \\
\text { He scored a gole. } \\
\text { We are going to bild a house. } \\
\text { The roof has bloan away. } \\
\text { There is blud on the floor. } \\
\text { You must wosh your face. } \\
\text { I have my oan bike. } \\
\text { Can you read this wurd? } \\
\text { Don't tutch the wet paint. } \\
\text { I have a very bad coff. }\end{array}$ & $\begin{array}{l}\text { The coe had a calf. } \\
\text { Do not loase your pocket money. } \\
\text { I had to gosp for my breath. } \\
\text { The doove flew away today. } \\
\text { The dog ate his bon. } \\
\text { I druv there very quickly. } \\
\text { She has loast her bag. } \\
\text { Give me soam tea. } \\
\text { Can I cotch the ball? } \\
\text { The moath flew into the air. } \\
\text { Can I spreed butter on my bread? } \\
\text { The river was brode. } \\
\text { He has a brise on his knee. } \\
\text { She fell doan the stairs. } \\
\text { The flowers are in blum early. } \\
\text { Can you mosh the potatoes? } \\
\text { The children have goan away. } \\
\text { The lurd visited the town. } \\
\text { Sit down on the cutch. } \\
\text { The boff of the tree broke. }\end{array}$ \\
\hline
\end{tabular}

APPENDIX C

Homophone Sentences and Matched Control Sentences in the Homophone Sentence Evaluation Task

Homophone Sentences

He through away his apple.

The driver will be build for the damage to the car.

The son is shining in the sky.

The cows went with the rest of the heard.

The people were happy to be at piece after the war.

The driver pushed on the break to stop.

There was won train during the next hour.

\section{Control Sentences}

He though away his apple.

The driver will be bald for the damage to the car.

The sure is shining in the sky.

The cows went with the rest of the head.

The people were happy to be at pierce after the war.

The driver pushed on the breath to stop.

There was once train during the next hour. 


\section{Appendix C (Continued)}

\begin{tabular}{|c|c|}
\hline Homophone Sentences & Control Sentences \\
\hline $\begin{array}{l}\text { He hammered in the steak to hold the rope for } \\
\text { the tent. }\end{array}$ & $\begin{array}{l}\text { He hammered in the stalk to hold the rope for } \\
\text { the tent. }\end{array}$ \\
\hline The young soldier was a bowled fighter. & The young soldier was a both fighter. \\
\hline She had not scene the book before. & She had not sewn the book before. \\
\hline The mayor was sold to the farmer. & The major was sold to the farmer. \\
\hline Mother is ceiling the letter ready to post it. & Mother is scalding the letter ready to post it. \\
\hline $\begin{array}{l}\text { The old people liked to talk about what } \\
\text { they did in the passed. }\end{array}$ & $\begin{array}{l}\text { The old people liked to talk about what they did in } \\
\text { the path. }\end{array}$ \\
\hline The boy did not know, so he guest an answer. & The boy did not know, so he guarded an answer. \\
\hline $\begin{array}{l}\text { There were puddles on the ground after the } \\
\text { reign came down. }\end{array}$ & $\begin{array}{l}\text { There were puddles on the ground after the the } \\
\text { ruin came down. }\end{array}$ \\
\hline
\end{tabular}

APPENDIX D

Items of the Word-Meaning Control Task

\begin{tabular}{|c|c|}
\hline Homophone Items & Matched Control Items \\
\hline $\begin{array}{l}\text { through } \\
\text { to heat up } \\
\text { smile at } \\
\text { go between } \\
\text { sent into air }\end{array}$ & $\begin{array}{l}\text { though } \\
\text { send into air } \\
\text { too many } \\
\text { stay up late } \\
\text { even if }\end{array}$ \\
\hline $\begin{array}{l}\text { build } \\
\quad \text { to read words } \\
\text { to make something } \\
\text { asked to pay } \\
\text { askid a lot }\end{array}$ & $\begin{array}{l}\text { bald } \\
\text { started up } \\
\text { bare head } \\
\text { bery hot } \\
\text { _ cried out }\end{array}$ \\
\hline $\begin{array}{l}\text { son } \\
\text { next } \\
\text { light } \\
\text { child } \\
\text { push }\end{array}$ & $\begin{array}{l}\text { sure } \\
\text { beach } \\
\text { _ open } \\
\text { _ cold } \\
\text { _certain }\end{array}$ \\
\hline $\begin{array}{l}\text { heard } \\
\text { box of toys } \\
\text { listened to } \\
\text { cut up } \\
\text { group of cows }\end{array}$ & $\begin{array}{l}\text { head } \\
\text { _give thanks } \\
\text { face } \\
\text { put away } \\
\text { truck }\end{array}$ \\
\hline $\begin{array}{l}\text { piece } \\
\ldots \text { part of } \\
\ldots \text { quiet } \\
\text { put away } \\
\text { room }\end{array}$ & $\begin{array}{l}\text { pierce } \\
\text { run fast } \\
\text { _ small bag } \\
\text { make hole } \\
\text { big pool }\end{array}$ \\
\hline $\begin{array}{l}\text { break } \\
\text { smash } \\
\text { find } \\
\text { f slow down } \\
\text { scamp out }\end{array}$ & $\begin{array}{l}\text { breath } \\
\text { child's bed } \\
\text { cover for book } \\
\text { air from lungs } \\
\text { person's chest }\end{array}$ \\
\hline $\begin{array}{l}\text { won } \\
\text { first in race } \\
\text { a road } \\
\text { a number } \\
\text { leave it alone }\end{array}$ & $\begin{array}{l}\text { once } \\
\quad \text { ride } \\
\text { _ at one time } \\
\text { _ baked a loaf } \\
\ldots \text { existed }\end{array}$ \\
\hline $\begin{array}{l}\text { steak } \\
\text { meat } \\
\text { stick } \\
\text { rose } \\
\text { travel }\end{array}$ & $\begin{array}{l}\text { stalk } \\
\ldots \text { part of a plant } \\
\text { a house } \\
\quad \text { a bird } \\
\text { _ end of a story }\end{array}$ \\
\hline
\end{tabular}

\section{Appendix D (Continued)}

\begin{tabular}{|c|c|}
\hline Homophone Items & Matched Control Items \\
\hline $\begin{array}{l}\text { bowled } \\
\text { without fear } \\
\text { not fresh } \\
\text { loaded up } \\
\text { threw ball }\end{array}$ & $\begin{array}{l}\text { both } \\
\text { the two } \\
\text { a ship } \\
\text { a tree } \\
\text { the earth }\end{array}$ \\
\hline $\begin{array}{l}\text { scene } \\
\text { looked at } \\
\text { cooked well } \\
\text { pile of stones } \\
\text { view of place }\end{array}$ & $\begin{array}{l}\text { sewn } \\
\text { joined with thread } \\
\text { _ planted seeds } \\
\text { _ran very fast } \\
\text { _did go away }\end{array}$ \\
\hline $\begin{array}{l}\text { mayor } \\
\text { a horse } \\
\text { important person } \\
\text { large bush } \\
\text { a chair }\end{array}$ & $\begin{array}{l}\text { major } \\
\quad \text { army leader } \\
\ldots \text { locked up } \\
\text { good child } \\
\text { _person making }\end{array}$ \\
\hline $\begin{array}{l}\text { ceiling } \\
\text { letting out } \\
\text { closing up } \\
\text { lack of food } \\
\text { top of room }\end{array}$ & $\begin{array}{l}\text { scalding } \\
\text { tell off bad child } \\
\text { to be careful } \\
\text { pay up money } \\
\text { p burn with hot water }\end{array}$ \\
\hline $\begin{array}{l}\text { passed } \\
\text { many people } \\
\text { called out } \\
\text { long ago } \\
\text { londed over }\end{array}$ & $\begin{array}{l}\text { path } \\
\quad \text { a piece } \\
\text { to count up } \\
\text { _very sad } \\
\text { place to walk }\end{array}$ \\
\hline $\begin{array}{l}\text { guest } \\
\text { small animal } \\
\text { thought it could } \\
\text { person visiting } \\
\text { watching the sky }\end{array}$ & $\begin{array}{l}\text { guarded } \\
\text { writing on paper } \\
\text { came down } \\
\text { looked after } \\
\text { showed the way }\end{array}$ \\
\hline $\begin{array}{l}\text { reign } \\
\text { to be sick } \\
\text { to be king } \\
\text { stay at home } \\
\text { water from sky }\end{array}$ & $\begin{array}{l}\text { ruin } \\
\text { tell the truth } \\
\text { damage } \\
\text { sweep } \\
\text { _part of house }\end{array}$ \\
\hline
\end{tabular}


APPENDIX E

Homophone and Matched Control Items in the Homophone Semantic Decision Task

\begin{tabular}{ll}
\hline \multicolumn{1}{c}{ Homophone Items } & \multicolumn{1}{c}{ Control Items } \\
\hline through-sent into the air & $\begin{array}{l}\text { though-sent into the air } \\
\text { buld-asked to pay } \\
\text { build-asked to pay }\end{array}$ \\
son-light & $\begin{array}{l}\text { sure-light } \\
\text { head-group of cows } \\
\text { heard-group of cows }\end{array}$ \\
piece-quiet & $\begin{array}{l}\text { breath-slow down } \\
\text { once-number before two } \\
\text { break-slow down }\end{array}$ \\
won-number before two & stalk-pointed stick \\
steak--pointed stick & both-without fear \\
bowled-without fear & sewn-used eyes \\
scene-used eyes & major-a horse \\
mayor-a horse & scalding-closing up \\
ceiling-closing up & path-long ago \\
passed-long ago & guarded-thought it could \\
guest-thought it could & ruin-water from sky \\
reign-water from sky &
\end{tabular}

(Manuscript received January 20, 1994;

revision accepted for publication December 7,1994 .) 